\title{
Reversal of Cancer by Dual Strategy?
}

\author{
Mario Gosalvez \\ Laboratorio y Servicio de Bioquímica Experimental, Clínica and Hospital Universitario Puerta de Hierro, Madrid, Spain. \\ Email: dmg.secre@gmail.com
}

Received February 21 ${ }^{\text {st }}, 2013$; accepted March 22 ${ }^{\text {nd }}, 2013$; accepted March 29 $9^{\text {th }}, 2013$

Copyright (C) 2013 Mario Gosalvez. This is an open access article distributed under the Creative Commons Attribution License, which permits unrestricted use, distribution, and reproduction in any medium, provided the original work is properly cited.

\begin{abstract}
I present herewith a concise historic account of our development of the new technique for cancer therapy: Reversal of Cancer by Dual Strategy. This new method is based on the possible correction of the mitochondrial filamentation defect of tumors plus minor cytotoxicity addressed to the anoxic and fagocitic tumor's redoubts, using the administration of the anticancer agents with a chrono-therapeutic emphasis on the patient's mobility. Such methods probably will reach patients in the near future with the collaboration of private clinical trials mainly at least in the USA, Europe and Japan. Only the more essential references of this effort are provided.
\end{abstract}

Keywords: Cancer Reversal; Mitochondrial Filamentation; Personal Mobility Chronotherapy; Mitochondrial Glycolysis; Respiration; Anoxic and Fagocitic Tumoral Redoubts

\section{Introduction and Antecedents}

That cancer can be reversed, is a familiar concept for those with clinical experience in treating cancerous tumors. Cancers in their evolution from the moment of detection until perhaps the patient's death, suffer, on many occasions, accelerations, stabilizations or spontaneous partial regressions, whether they are not treated at all or whether they receive effective or ineffective treatments. The experienced clinical oncologist is frequently used to seeing these variations in the rhythm of tumors. Often they are paradoxical or on occasions they are related to psychic aspects or the social life of the patient, or other peculiarities of each case.

The concept of the possibility of increasing the potentiality or of inducing the cancerous cell towards its reversal, begins, at the experimental level, in 1971 with the works of the Puck, Pastan y Friend groups [1-3] when they observe that the cyclic AMP in epithelial cells in cultivation or dimethyl sulfoxide in leukemic cells in culture are capable of inducing a reverse transformation [4] or a normal differentiation [5]. These lines of work did not culminate in a clinical application, despite the experimental effort of various groups, first because those agents were not able to cure transplanted mice tumors, the key that was then obligatory in experimental cancerology in order to step from a drug to the clinic, or

*Former Head (1970-2010). secondly, because they were compounds of great toxicity and a multitude of actions.

From 1975 to 1982, I put forward a new membrane hypothesis [6,7] “The Zipper Mechanism”, which postulated a close relationship of the plasma membrane with the nucleus and the cellular organelles through contractile microfilament systems. In this theoretical hypothesis the cellular differentiation would be measured through modifications of genetic expression, changes in cellular growth and variations of membrane properties which would be inducible using chelating agents that would act on respiratory complexes of the plasma membrane. Based on this hypothesis I proposed that the L-thioproline should be an inducer of the reverse transformation, and was able to demonstrate that this derivative of proline amino acid generates the restoration of contact inhibition in HeLa cells [8]. The recovery of inhibition of growth by contact in the cancerous cell was the most pronounced characteristic in the processes of reverse transformation which cyclic AMP causes [4].

Subsequent studies with several collaborators initially demonstrated that under adequate experimental conditions Sodium L-thioproline at least:

1) Induces a reduction in the growth rate of several cellular lines without causing cellular death;

2) This diminution of cellular growth is accompanied by a morphological change, characteristic, to bigger and longer cellular forms;

3) The morphological change is accompanied by an 
enrichment of the cells with contractile microtubules and microfilaments which appear better organized;

4) The treated cultures present a great reduction in cellular saturation density. So they recover the growth inhibition by cellular contact;

5) The cells so modified by thioproline present an isoenzimatic change of at least two enzymes of the glycolysis, pyruvate kinase and the phosphofructokinase, to less neoplastic forms, a fact that is accompanied by a decrease in lactic acid production and glucose consumption. Aerobic glycolysis is a key characteristic of cancerous cells;

6) The mitochondria of modified cells degenerate and present uncoupled oxidative phosphorylation;

7) The modified cells have more cellular communication couplings, more water, more proteins and less DNA. Their synthesis of RNA, DNA and proteins is less and sodium transportation is 10 times smaller.

All this data suggested to me that the treatment of cultures of neoplastic cells with thioproline produces a cellular modification towards normality and makes the cells unviable in culture [9]. The mitochondrial degeneration was not explained at that time, 1983.

\section{Reversal of Cancer and Quelamycin}

\section{Reversal of Cancer by Dual Strategy}

In January 1980, The Lancet published a clinical study with thioproline [10]. This pilot test, not controlled, threw up a number of complete regressions in a peculiar and rare type of patients, epidermoid cancers, well differentiated of head and neck with pulmonary metastasis. The type of person suited to follow the effects of a cancer reversal agent to normality [10]. The attention generated by the first of this type of compounds that had generated clinical efficiency in humans created a controversy which made The Lancet publish an editorial requesting more clinical testing [11]. But the suggested therapeutic activeity was not corroborated [12,13].

I had developed, with funding from the United States National Cancer Institute, my first citototoxic for the anoxic redoubts of tumors, quelamycin, which apparently was better than adriamycin because the cardiotoxicity was decreased, among other things, forming the ferric complex. Quelamycin shows a good initial clinical interest [14]. But its manufacture could not be considered, at that time, by pharmaceutical companies because the minimum fraction of free iron accompanying the formulation following the liofilization of the complex could not be determined except by a theoretical calculation. Although we provided a possible better formulation and some negative cardiac biopsies [14] and a chemical study on the nature of this metallic complex, its production was finally not considered appropriate for pharmacies [15].
With thioproline and its first analogue we introduced some controlled clinical testing [16], in addition to the proposal of possible synergies if the compounds were combined with quelamycin and derivatives $[17,18]$. At that time, the 1990-1992 biennium, the concept of reversal of cancer by dual strategy was born. The combination of modifying agents towards reversal to normality with citotoxics aimed at the anoxic and fagocitic redoubts of the tumors.

With quelamycin I suggested also the possibility of making derivatives with activated oxygen in order to make a stable compound that could be combined with its derivatives and with the reversal agents, with a cronotherapeutic emphasis on the patient's mobility [19] because after detailed scrutiny I found that the difference of positive and negative clinical trials was due surely to the different times of administering the agents.

I was concerned with the thioproline irreproducibility perhaps because there could be diverse kinds of causes to explain the disagreements [20] but the exact moment to administer thioproline emerged as the most important in that irreproducibility in 1992 [19]. Due to that I developed, over the following years, studies on thioproline mechanism of action, discovering its effects on mitochondrial filamentation [21], which culminated in explaining the suspected requirement of administering thioproline and its analogues at the moment of awakening and quelamycin and its derivatives at bed time [19].

As had always been done with the Spanish clinical assays $[14,16]$, once when this was performed thus in this way, by chance, in the first pilot studies, which produced unexpected result. Naturally this was necessary, I at last know so now, so as to be able induce the due correction of the mitochondrial filamentation defect of cancer [21].

\section{Conclusion}

I have recently proposed that Mitochondrial Filamentation could be considered a new molecular target and proposed a multinational clinical study of this new technique. The targets of this therapeutic modality could be the global component of all human cancers: The respiretory defect of mitochondrial filamentation plus the anoxic and fagocitic cellular bastions of human tumors [21]. A review of our studies on the aerobic glycolysis of the tumoral cells was published recently on-line [22]. And also a concise account of the methods to be developed for some future possible applications of mitochondrial filamentation was also published [23]. A summary of my life of research and thinking between cancer and mitochondria entitled Cancer Reversal and Mitochondrial Filamentation will be presented to another Journal concomitantly with this paper. 


\section{REFERENCES}

[1] A. V. Hsie and T. T. Puck, "Reversion of Hamster Kidney Epithelial Cells with Cyclic AMP," Proceedings of the National Academy of Sciences of the United States of America, Vol. 68, No. 2, 1971, pp. 358-361. doi:10.1073/pnas.68.2.358

[2] G. S. Johnson, R. H. Friedman and I. Pastan, "Morphological Change of Epithelial Cells after Treatment with Dibutyril Cyclic AMP," Proceedings of the National Academy of Sciences of the United States of America, Vol. 68, No. 2, 1971, pp. 425-429. doi:10.1073/pnas.68.2.425

[3] C. Friend, W. Scher, J. G. Holland and T. Sato, "Normal Differentiation of Leukemia Cells," Proceedings of the National Academy of Sciences of the United States of America, Vol. 68, 1971, p. 3678.

[4] T. T. Puck, "Reverse Transformation, Membranes, Cancer and Microfilaments," Proceedings of the National Academy of Sciences of the United States of America, Vol. 74, No. 10, 1977, pp. 4491-4495. doi:10.1073/pnas.74.10.4491

[5] Y. Honma, T. Kasukabe, J. Okabe and M. Hozumi, "Prolongation of Survival Time of Mice Inoculated with Myeloid Leukemia Cells by Inducers of Normal Differentiation," Cancer Research, Vol. 39, No. 8, 1978, pp. 31673171.

[6] M. Gosálvez, "Bases for the Design of Pharmacological Effectors Acting on Plasma Membrane Receptors,” Biochemical Society Transactions, Vol. 9, No. 1, 1981, pp. 151-152.

[7] M. Gosálvez y Gosálvez, “The Zipper Mechanism,” Madrid, 1982.

[8] M. Gosálvez, C. Vivero and I. Alvarez, "Restoration of 'Contact Inhibition' in Tumor Cells in Tissue Culture with Thiazolidin-4-Carboxylic Acid,” Biochemical Society Transactions, Vol. 7, 1979, pp. 191-192.

[9] M. Gosálvez, “Thioproline and Reversal of Cancer,” Lancet, Vol. 321, No. 8333, 1983, p. 1108. doi:10.1016/S0140-6736(83)91947-5

[10] A. Brugarolas and M. Gosálvez, "Treatment of Cancer by an Inducer of Reverse Transformation,” Lancet, Vol. 315, No. 8159, 1980, pp. 68-70. doi:10.1016/S0140-6736(80)90494-8

[11] Editorial, “Reversal of Cancer,” Lancet, Vol. 1, 1983, pp. 799-800.

[12] F. Boccardo, A. Barbieri, L. Canobbio, D. Guarneri, M. Merlano and R. Rossi, "Phase II Trial of Thioproline in Advanced Epidermoid Head and Neck Tumors,” Cancer Treatment Reports, Vol. 66, 1982, p. 585.
[13] P. Alberto, “Thioproline (Norgamem): A Useless Drug in the Treatment of Squamous Cell Carcinoma,” European Journal of Cancer, Vol. 17, No. 9, 1981, pp. 1061-1062. doi:10.1016/S0277-5379(81)80014-4

[14] H. Cortes-Funes, A. Brugarolas and M. Gosalvez, "Quelamycin: A Summary of Phase I Clinical Trials,” Cancer Chemo- and Immunopharmacology Recent Results in Cancer Research, Vol. 74, 1980, pp. 200-206. doi:10.1007/978-3-642-81488-4_25

[15] H. Kozlowski, K. Drabent, H. Seysuck and M. Gosalvez, "Mossbauer, Magnetic and Thermogravimetric Studies on Adriamycin Ferric Complexes,” Inorganica Chimica Acta, Vol. 66, 1982, pp. 189-192. doi:10.1016/S0020-1693(00)85811-9

[16] A. Brugarolas and M. Gosalvez, "Preliminary Clinical Results with Norgamem (Thioproline) and Revercan (2Amino-2-Thiazoline): The First Inducers of Reverse Transformation,” In: Mathe, Bonnadona and Salmon, Eds., Adjuvant Therapies of Cancer, Springer-Verlag, Berlin, 1982, pp. 346-350.

[17] M. Gosálvez, M. Blanco and C. Fernandez, "Synergy between Quelamycin and Thioproline," Proceedings of the American Association for Cancer Research, San Diego, 20-23 May 1992.

[18] M. Gosalvez, M. Blanco, M. Bueno and R. Balaguer, “Treatment of Leukaemia 1210 Intravenous Transplants with Tumor Modifiers, Redoubt Cytotoxics and Minor Tranquilizers,” In: G. Lubec and G. A. Rosenthal, Eds., Aminoacids. Chemistry, Biology and Medicine, Escom Sciences Publishers, 1990, pp. 704-711.

[19] M. Gosalvez, “Cancer Reversal by Dual Strategy,” Editorial Gober, Madrid, 1992.

[20] M. Gosálvez, "On the Irreproducibility of Thioproline," Biomedicine \& Pharmacotherapy, Vol. 36, No. 8-9, 1982, pp. 387-388.

[21] M. Gosalvez, "Mitochondrial Filamentation: Some Methods of Isolation and Assay," IOSR Journal of Pharmacy and Biological Sciences, Vol. 4, No. 4, 2012, pp. 37-39. doi:10.9790/3008-0443739

[22] M. Gosalvez, "Metabolic Control of Respiration and Glycolysis of Tumoral Cells," Advances in Biological Chemistry, Vol. 3, No. 1, 2013, pp. 86-89. doi:10.4236/abc.2013.31011

[23] M. Gosalvez, "Methods to Be Developed for Some First Future Applications for Mitochondrial Filamentation," Open Journal of Biophysics, Vol. 3, No. 1A, 2013, pp. 51-53. doi:10.4236/ojbiphy.2013.31A006 